\title{
Ethical Issues in Academic Authorship: A Study on Group Writing
}

\author{
Wan Mohd Khairul Firdaus Wan Khairuldin ${ }^{1}$ \\ Wan Nur Izzati Wan Nor Anas ${ }^{2}$ \\ Roslan Umar ${ }^{1}$ \\ Mohd Khairul Amri Kamarudin ${ }^{1}$ \\ Abdul Hanis Embong3 \\ ${ }^{1}$ Faculty of Islamic Contemporary Studies, Sultan Zainal Abidin University, \\ Gong Badak Campus, Terengganu, Malaysia \\ ${ }^{2}$ Academy of Islamic Studies, University of Malaya, Malaysia \\ ${ }^{3}$ Centre for Foundation and Liberal Education, University Malaysia Terengganu, Malaysia
}

DOI: https://doi.org/10.36941/ajis-2022-0020

\begin{abstract}
In the academic world, the authors and the publication of academic writing are inseparable. By publishing academic writing, academicians can improve their performance and increase their visibility in academia. However, academic writing is not an easy thing, as it is directly tied to the ethics of academic authorship. However, there have been several forms of unethical identified in academic authorship. Among them is the unethical placement of the author's name. This dishonesty certainly has a negative impact on the world of scholarship because those who are in this world of scholarship are said to have the nature of high integrity. Among the main causes of this problem is the need to achieve annual target. Is academic authorship tied to the ethics of academic authorship? What are the forms of dishonesty in academic authorship? There are two main objectives in solving the question. First, explain the ethics of academic authorship. Second, explain the forms of dishonesty specifically related to naming groups of authors in academic writing. The documentation method is carried out to obtain data related to ethics and forms of dishonesty in academic writing to achieve these objectives. The collected data were analyzed by content analysis to explain the inaccuracies in author nomination in academic writing. This study found that academic authorship is bound by its ethics as authoritative and recognized writing. One of the most common frauds is to put the name of an author or a group of authors who contributed to academic authorship. However, there are two main forms of academic dishonesty: putting the name of the individual as the author despite not contributing to the authorship and not putting the name of the contributing author in the authorship. This practice violates the ethics of academic authorship.
\end{abstract}

Keywords: Ethics, Academic Authorship, Academic Writing, Unethical

\section{Introduction}

Academic writing is systematic writing that is usually produced by academics. According to Day (1983), academic authorship is a written and published report to explain research results. According 
to the American Psychological Association, 2001), academic authorship is a form of writing that is formal in presenting ideas, concepts, etc., by involving the author to refer to authoritative sources. For example, journals, scholarly books and so on. Authorship academic is different from authorship or other writing because academic authorship has a clear style of authorship and is academic (Davis, 1997).

In addition, academic writing is produced through a high discipline in obtaining specific facts. In fact, academic writing is also concerned with the validity of facts. Academic writing also focuses on authors. This is because authors are essential individuals in producing academic authorship. Therefore, authors have certain ethics in producing excellent and genuine academic authorship (Derntl, 2014).

In general, group authorship for scholarly writing can be defined as writing done by more than one individual in an article (Glaenzel et al. 2004; Katz et al. 1997). This writing is written academically and involves academics or experts in their respective fields. In addition, this writing also sometimes involves experts in the field when it involves field studies (Wuchty, Jones, \& Uzzi, 2007). According to Mad Shah (2004), collaboration in writing is a form of fusion of energy, ideas, knowledge and abilities of each researcher. The work will ultimately result in a high value of input, creative and innovative compared to writing individually. In addition, this group writing also increases productivity as well as the scientific impact on the writing (Bales et al., 2014; Claudel, Massaro, Santi, Murray \& Ratti, 2017)

However, the advantages of group writing are marred by various ethical issues either in Malaysia or abroad. In the pursuit of this annual KPI requirement through group writing, an issue arises that destroys the integrity of academics through the non-contribution of each nominee in the writing conducted (Salleh, 2011; Yusoff, 2017; Khairuldin, 2016). Various terms have been mentioned by scholars that reflect this matter including honorary authorship guest authorship, cartel coauthorship, free rides and so on (Newman \& Jones, 2005; Roosfa Hashim, 2006; Osborne \& Holland 2009; Salleh, 2011; Bavdekar, 2012).

According to Jennings \& El-adaway (2012), ethical issues in academic writing are more likely to be referred to as cartel co-authorship. Cartel co-authorship refers to the result of academic writing that is apparently produced by a group of academics (three to five people) as co-authors, but is actually only wrote by one of them. The namesake for the rest of the other writers usually does not have any contribution or does not achieve a significant contribution for that writing. Yet, they reap the same benefits as writers who have indeed contributed significantly in such writing (Morris \& Hayes, 1997; Stroebe, Diehl \& Abakoumkin, 1996). This is contrary to authorship guidelines [e.g., guidelines by the Materials Research Society (MRS) and the American Psychological Association (APA)] which require contributions for each nominee to be significant to the task performed (Osborne \& Holland, 2009).

Nowadays, academic writing has received a lot of criticism due to a handful of writers who commit misconduct in publishing (Salleh, 2012). Among the wrongdoings include "free-riderism", honorary authorship, ghost authorship and so on. Therefore, this article will explain some of these forms of misconduct in more detail.

\section{Methodology}

This study collects the data set by using both (Classic \& modern) documents then will be analyst through the content analysis method. Content analysis is used to particularize and explaining the interpretations of the documents. As a result, from this analyst will lead to a systematic conclusion (Krippendorff, 2004; Yusof, 2004). Hence, the analysis result for this article will explain the forms of unethical issues in academic authorship or writing, especially in groups of authors or group writing.

\section{Findings}

This article will analyze two aspects. First, the ethics of academic authorship is primarily in the 
placement of the author's name in academic authorship. Second, dishonesty and unethical issues in academic authorship include placing or crediting an individual's name that violates the ethics of academic authorship.

The author in academic writing is an individual who contributes both physically and mentally, such as ideas to the content contained in academic authorship. Such contributions are based on scientific research to form credible writing (Iammarino, O'Rourke, Pigg \& Weinberg, 1989). Clement (2014) defines an author as an individual or those who have contributed to information and played a significant role in academic writing. The contributions include research, writing or compiling such information in the form of academic authorship. Therefore, it can be concluded that the author refers to a person who contributes in manifesting knowledge to a form of academic authorship by going through several procedures such as adding information, compilation and so on.

Academic authorship and the author itself are interrelated with each other. This is because every academic authorship should give credit to the author who produced it (Mandal \& Parija (2013). This is the main ethics of academic authorship. Therefore, credit to the author will certainly have implications on the academic or work of the author.

In academic authorship, the number of authors is not limited to one author only (Hundley, van Teijjlingen \& Simkhada, 2013). The number of authors can occur in a large number of authors known as co-authors. However, the large number of authors is limited based on the conditions given by each publication journal. This is because each different publication journal will impose other conditions. According to Pittella, Andriolo, Barbosa and Santos (2014), the pressure on those in the academic world such as lecturers to produce academic authorship publications is very high. This is also a factor why there are many authors named in academic authorship.

Credit to the author is based on the author's contribution in producing academic authorship. The contribution is given to at least one component in academic authorship. According to VuckvicDekic (2003), credit to an author in academic authorship is based on three conditions. First, a significant contribution to concept, design and data acquisition. Second, compiling articles and analyzing data and third, consenting to the edited academic authorship to be published. Those conditions must be met to obtain the title of co-author.

However, there are two main reasons for placing an author's name in academic authorship: the appreciation and responsibility factors (Strange, 2008). The first factor aims to appreciate his contribution in producing academic authorship and scholarly publications. However, the second factor is that the author will be responsible for such academic authorship.

\subsection{The Arrangement of The Author's Name in Academic Writing}

Generally, academic authorship can be produced by one author or a group of authors. However, there are rules or ethics in naming an author, even if the author consists of more than one author. Therefore, all those appointed or designated as qualified authors in authorship should be listed and named.

Every author must also have committed to the writing of the academic manuscript. In fact, each of the authors is responsible for every component of the academic authorship. This also means that each author should be accountable for the integrity of academic authorship from the beginning of its production until it is published (Vuckvic-Dekic, 2003).

In academic authorship with many authors, authorship's placement of names or credits becomes complicated. The contribution's portion by each author cannot be simplify judged. Sometimes it causes all authors to demand from each other for more significant credit in academic authorship. Therefore, the question arises when the writing has more than one number of authors. How does the order of the author? 
According to Tscharntke et al. (2007), the first or main author should be the author who makes the most contributions in academic authorship. However, the order of the second, third, and subsequent author names is based on the author's contribution, alphabetical order, or seniority. This is also mentioned by Hunt (1991) when the order of the author's name reflects the author's contribution. The order of the author's names shows a descending order or the smaller their contribution. For example, the first author is the main contributor to the writing. Whereas the second author contributed less than the first author. At the same time, the contribution of the third author is less than the contribution of the second author.

Riesenberg and Lundberg (1990) suggested the order of author in authorship based on a few factors; the first author is the author who performs the most contribution to authorship tasks, especially in composing the writing. The other factors are based on the amount of contributions, even if not the lead author. The third factor is the senior author's name placed in the last order regardless of his contribution.

According to Tscharntke et al. (2007,) there are four approaches in author group crediting in academic authorship. First, an approach known as Sequence determines credit (SDC). The order of the author's name describes the author's contribution in academic authorship in descending order. The first author is the largest contributor to academic authorship, while the last author is the least contributor. The second approach is to list all authors based on the alphabetical order of the author's name. However, this approach is more appropriate for situations where all authors contribute to authorship at the same rate. This approach is known as the Equal Contribution (EC) approach. The third approach highlights the importance of the first author and the last author. This is known as the First-last-author-emphasis (FLAE). While the fourth approach is Percent-Contribution-Indicatd (PCI) allows authors to express their contribution in the form of percentages or by using a scoring system.

It is concluded that the author who contributes the most to the production of academic authorship will be placed first or foremost. Similarly, the next authors are named based on their contributions.

In addition, to avoid misunderstandings, especially in placing the name of the group of authors in academic authorship, the authors need to discuss in advance the placement and contributions. This is very important because the authors will be responsible for their contributions and avoid conflicts between the authors themselves (Takang, Kweku \& Zotor, 2017). It will reduce dishonesty in academic authorship (Patience, Galli, Patience, \& Boffito, 2019).

\subsection{The Ethical Issues In Academic Authorship}

In authorship, the author is emphasized on the discipline in placing or crediting the author of academic authorship. However, there are situations of unethical authorship or referred to as academic authorship fraud.

According to Patience et al. (2019), there are five forms of unethical authorship; coercive authorship, honorary authorship, guest authorship, gift authorship and ghost authorship. While Gaber (2011) believes there are four forms of unethical writing in general. First, gift authorship, second prestige authorship, third ghost authorship and fourth honorary authorship. Sung (2017) also lists unethical authorship such as gift authorship (honorary or guest), ghost, swapping and theft authorship.

Although the list of unethical authorship practices varies when a mentioned practice contradicts the ethics of authorship, the practice is automatically unethical in authorship. This can be seen based on the contradiction of such practices with the ethics of authorship.

Gift authorship is placing an author's name on an academic authorship list over a sense of respect. (Maronpot, 2011) including the supervisor, senior researcher, colleague, etc. (Sung, 2017). Generally, these gift authors will agree to be listed as authors. This aims to improve their performance in careers especially careers that are in the academic field. This practice strongly violates the ethics of authorship (Gasparyan, Ayvazyan \& Kitas, 2013). In contrast, these gift authors did not 
contribute anything related to authorship (Smith, 1994; Flanagin et al., 1998),

Guest authorship is an individual who is placed as an author but does not contribute either to the design component, data analysis or authorship. Generally, the practice happened to those wellknown in the particular research field (Schofferman, 2015). In addition, these guest authors are paid because their names are listed as authors (Murray, Brophy \& Palepu, 2010).

Honorary authorship is the name of an individual who is placed as an author, but the individual does not qualify as an author (Kressel and Dixon (2011). Honorary authors usually involve several factors. First, the academic article author places honorary authors on a reciprocal basis as honorary authors will put the author's name in the next academic article. Second, because the academic writing will likely be accepted if the honorary authors are individuals who have expertise in the field (Fong \& Wilhite, 2017). There is also an opinion that suggested guest authors are honorary authorship (Kumar, 2018).

Ghost authorship is the practice of not putting the name of someone who has made a significant contribution to the production of academic authorship and is eligible for the author's title. Ghost authorship can occur when the author is paid to produce academic authorship (Maronpot, 2011). Ghost authorship is used in two situations. First, it refers to professional authors who are usually hired to produce authorship. Second, it refers to authors who contribute to the production of academic authorship but are not listed as authors (Wager, 2003).

\section{Discussion}

In general, academic dishonesty in group writing can be divided into two parts. Among them is the practice of including the author's name who did not make a significant contribution and dropping the name of the author even though he made a significant contribution. Unfortunately, both of these practices occur frequently in academic writing nowadays.

Among the issues that caused this to happen were the excessive work constraints on the academy and the high publishing fees imposed by the journal's publisher. Furthermore, predatory journals also take advantage of this by charging high publishing fees without adequately reviewing the writing.

The thing that can be done is to review the method of naming in academic writing. The classical writing tradition emphasizes individual writing is the best method of maintaining the quality and ethics of writing. However, in some cases, group writing provides an excellent perspective if done correctly.

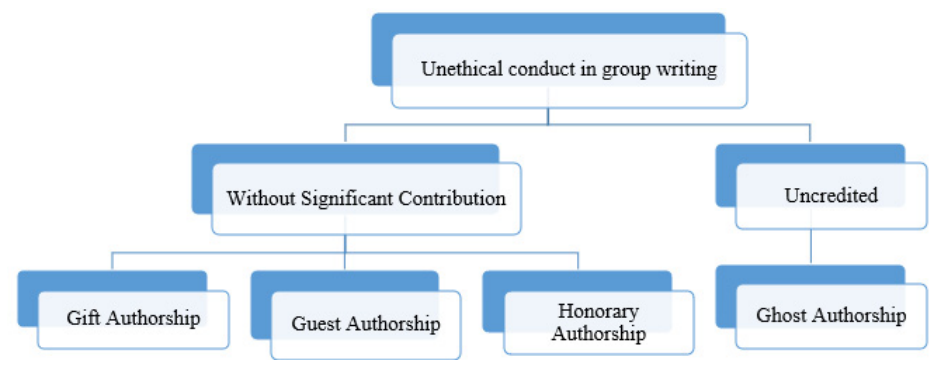

\section{Conclusion}

Crediting individuals who do not contribute to academic authorship or even not crediting the name of an author who does not contribute to academic authorship is a practice and act contrary to the ethics of academic authorship. The authenticity of each academic authorship produced must be maintained. It will be held accountable for any questions on the author or group of authors related to 
each production of academic authorship. Therefore, academics need to maintain integrity in each of their jobs, especially concerning the production of academic authorship or writing, so that the academic world is always held in high esteem.

\section{Acknowledgement}

This article is a part of research under Fundamental Research Grant Scheme (FRGS), FRGS/1/2019/SSIo3/UNISZA/o2/3 (Pembentukan Parameter Kepengarangan Berkumpulan Penulisan Akademik Berintegriti Berteraskan Islam: Penilaian Semula Kepada Dasar Penulisan Akademik di Malaysia), and is supported by the Ministry of Education and Universiti Sultan Zainal Abidin (UniSZA).

\section{References}

American Psychological Association (2001). Publication Manual of the American Psychological Association. 5th ed.Washington, D.C.:

Clement, T.P. Authorship matrix: A rational approach to quantify individual contributions and responsibilities in multi-author scientific articles. Sci Eng Ethics. 20(2):345-361

Davis, M. (1997), Scientific Papers and Presentations. San Diego: Academic Press.

Day, R.A. (1983) How to Write and Publish a Scientific Paper. Philadelphia: ISI Press.

Derntl, M. (2014). Basics of Research Paper Writing and Publishing, International Journal Technology Enhanced Learning, 6(2), pp. 105-123.

Eymard, J.H., Pittella, A.A., Barbosa, A.J.A. \& Santos, S.M.E. (2014). What qualifies a person to be an author of a research paper? Jornal Brasileiro de Patologia e Medicina Laborotorial, 50 (2).

Flanagin, A., Carey,L., Fontanarosa, P.B., Philips, S.G., Pace, B.P., Lundberg, G.D. (1998). Prevalence of Articles with Honorary Authors and Ghost Authors in Peer-reviewed medical journals. JAMA. 280(3). 222-224.

Gasparyan A.Y., Ayvazyan, L., Kitas, G.D. (2013). Authorship problems in scholarly journals: considerations for authors, peer reviewers and editors. Rheumatol Int. 33:277-284.

Hundley, E., van-Teijlingen \& Simkhada, P. (2013). Academic authorship: who, why and in what order? Health Renaissance. 11(2). 99-101.

Iammarino N.K., O'Rourke, T.W., Piggm R.M., Weinberg, A.D. (1989). Ethical issues in research and publication. J Sch Health. 59:101-124

Hassan, S. A., \& Khairuldin, W. M. K. F. W. (2020). Research design based on fatwa making process: An exploratory study. International Journal of Higher Education, 9(6), 241-246. doi:10.5430/ijhe.v9n6p241

Kumar, S. (2018), Ethical Concerns in the Rise of Co-Authorship and Its Role as a Proxy

Mandal, J \& Parija, S.C. (2013). Ethics of Authorship in Scientific Publication. Tropical Parasitol. 3(2). 104-105/

Maronpot, R.R. (2011). Responsible authorship and publication practices. Toxicol Pathol. 39:1029-1031.

Murray. S, Brophy, J., Palepu, A. (2010). Open Medicine's ghost and guest authorship policy. Open Med. 4 (1): e11e12. of Research Collaborations. Publications. 6(3):37.

Patience, G.S., Galli, F., Patience, P.A. \& Boffito, D.C. (2019). Intellectual contributions meriting authorship: survey results from the top cited authors across all science categories. PLoS ONE. 14(1). eo198117.

Schofferman, J. (2015). Ghost and Guest Authors: You Can't Always trust Who You Read. Pain Med. 16(3):416-420

Shuhari, M. H., Hamat, M. F., Basri, M. N. H., Khairuldin, W. M. K. F. W., Wahab, M. R., Alwi, E. A. Z. E., \& Mamat, A. (2019). CONCEPT of al-amanah (trustworthiness) and al-mas'uliyyah (responsibility) for human's character from ethical islamic perspective. Journal of Legal, Ethical and Regulatory Issues, 22(Special Issue 1), 1-5.

Smith R. (1994). Introductions. How to write a paper. London: Hall GM.

Strange K. (2008). Authorship: Why not just toss a coin? Am J Physiol Cell Physiol. 295(3). Pp. 567-575.

Takang, E.E., Kweku, M. \& Zotor, F.B. (2017). Publication Practices and Responsible Authorship:A review Article, J. Public Health Afr, 8(1). Pp. 36-42.

Tscharntke, T., Hochberg, M.E., Rand, T.A., Resh, V.H., Krauss, J. (2007). Author sequence and credit for contributions in multiauthored publications. PLOS Biology. 5(18). 13-14.

Wager, E. (2003), How to Handle Authorship Disputes: A Guide for Researchers, The Cope Report. Hampshire: COPE. 